\title{
Diferentes olhares do Turismo de Base Comunitária da Reserva Extrativista Marinha de Soure, Amazônia
}

\section{Different Views of Community Based Tourism of Marine Extractive Reserve of Soure, Amazonia (Brazil)}

\author{
Jônatas Bastos Soares, Ricardo Eustáquio Fonseca Filho
}

\begin{abstract}
RESUMO: As Reservas Extrativistas têm como proteção básica a sociobiodiversidade. Uma das alternativas de uso público sustentável se dá pelo turismo, que está sujeito a gerar impactos negativos. Assim, o presente trabalho aborda os diferentes olhares do Turismo de Base Comunitária (TBC) na Reserva Extrativista Marinha de Soure (RESEXMS). A pesquisa de cunho exploratório e estudo de caso se deu por meio de revisão bibliográfica, elaboração de instrumento de coleta de dados (questionários estruturados qualitativos) e 16 entrevistas a 11 representantes do conselho deliberativo (poder público, setor privado e sociedade civil organizada) e turistas. Complementarmente houve observação participante por meio de estágio voluntário na unidade de conservação. Como resultados observouse que o TBC é um importante transformador socioeconômico, cultural e ambiental, no entanto sendo necessário uma maior articulação dele enquanto participação ativa dos atores sociais, para maior efetividade de gestão da área protegida.
\end{abstract}

PALAVRAS CHAVE: Turismo; Reserva Extrativista; Amazônia; Unidades De Conservação; Gestão Participativa.

ABSTRACT: The basic function of extractive reserves is protecting sites' sociobiodiversity. One alternative for sustainable public use of extractive reserves is tourism, which may have negative effects on the reserves' socio-biodiversity. Therefore, the present work addresses different perspectives of Community-Based Tourism (CBT) in the Marine Extractive Reserve of Soure, Brazil. The exploratory research and case study presented in this work include a bibliographic review, qualitative structured questionnaires, and 16 interviews with 11 representatives of the deliberative council, which includes members from the government, the private sector and organized civil society as well as tourists. In addition, participation as an observer through a voluntary internship in the protected area. Results show that the CBT is an important transformation agent of the socio-economic, cultural, and environmental conditions of the reserve. However, it is necessary to increase its articulation as active participation of the stakeholders to improve the effectiveness of reserve management.

KEYWORDS: Tourism; Extractive Reserve; Amazônia; Natural Protected Area; Participative Management. 


\section{Introdução}

A relação entre os seres humanos e o meio ambiente é interligada, dependendo assim o bem-estar de um estar aliado com o outro. Porém, apesar desta não apenas estreita, mas relação conjunta, o meio ambiente vem sofrendo a ação antrópica desde muito tempo, sendo que a partir da revolução industrial houve um agravante nesta relação, onde os impactos causados pelas ações humanas passaram a ter mais força, em um convívio de destruição em que o ambiente é cada vez mais "degradado" para que os seres humanos possam retirar os recursos necessários para não apenas sua sobrevivência, mas para seu conforto, enxergando-o assim como algo aquém da própria natureza.

Desta forma, podemos afirmar que a relação turismo e meio ambiente é incontestável, uma vez que o turismo é realizado por ações humanas. Sendo que há cada vez mais procura, de pessoas que busquem alternativas além das grandes cidades em suas férias e finais de semana, a fim de terem contato direto com a natureza. A conservação prevê a exploração racional e o manejo contínuo de recursos naturais, com base em sua sustentabilidade.

Sendo de suma importância que o turismo, seja reavaliado em todas suas nuances, a fim de que sejam diminuídos os impactos causados por suas atividades.

O turismo exerce impactos significativos na vida das pessoas que viajam e também dos habitantes do destino visitado (SWARBROOKE, 2000; MEDEIROS; MORAES, 2013). Muitas preocupações com o meio ambiente foram surgindo nas últimas décadas, pois nem todos os recursos naturais são renováveis. $E$, principalmente, quando a atividade turística é realizada em ambientes naturais, é preciso elaborar planos e projetos com cautela, organização e em um âmbito multidisciplinar, pois estes abarcam diversas esferas do conhecimento, tais como: geografia, patrimônio, gestão e outras.

Portanto, quando se trata de turismo e citamos os impactos ambientais em um mundo globalizado também quando tratamos a respeito do uso humano quanto aos recursos, é notável o Turismo de Base Comunitária (TBC), um segmento do turismo, onde todo tipo de relação socioambiental é levado em conta, para que os impactos sejam minimizados e a população consiga ter papel ativo, sendo diretamente beneficiados pelo turismo.

É conveniente afirmar que a criação deste tipo de unidade de conservação (UC) se deu a partir da luta das próprias comunidades, representadas por povos como os seringueiros e indígenas. Chico Mendes foi um seringueiro que deu nome ao instituto gestor das UC federais, o Instituto Chico Mendes de Conservação da Biodiversidade (ICMBIO) e a uma das RESEX federais de mesmo nome:

Até 1984, a gente realizava os empates, mas não tínhamos muita clareza do que queríamos. Sabíamos que o desmatamento era o nosso fim e de todos os seres vivos existentes na selva. Mas a coisa terminava aí. As pessoas falavam: "Vocês querem impedir o desmatamento e transformar a Amazônia em santuário? Intocável?" Estava aí o impasse. A resposta veio através da Reserva Extrativista. Vamos utilizar a selva de forma racional, sem destruí-la. Os seringueiros, os índios, os ribeirinhos há mais de 100 anos ocupam a floresta. Nunca a ameaçaram. Quem ameaça são os projetos agropecuários, os grandes madeireiros e as hidrelétricas (RISSO, 2012, p. 132 apud MENDES, 1992). 
Sendo assim, os conflitos existentes durante muitos anos, permitiu que esta nova categoria de área protegida surgisse, demonstrando que a luta dos povos e comunidades resultou em algum fruto, para que principalmente a região da Amazônia passasse a ser protegida, preservando não apenas sua natureza e também a cultura dos povos que ali vivem. Como afirma Risso (idem):

\begin{abstract}
Nas reservas extrativistas nós vamos comercializar e industrializar os produtos que a floresta generosamente nos concede. Temos na floresta a bacaba, o tucumã, a copaíba, o mel de abelha, que nem os cientistas conhecem. E tudo isso pode ser exportado, comercializado. A Universidade precisa vir acompanhar a Reserva Extrativista. Estamos abertos a ela. A reserva extrativista é a única saída para a Amazônia não desaparecer. E mais, essa reserva não terá proprietários. Ela vai ser um bem comum da comunidade. Teremos o usufruto, não a propriedade (apud MENDES, 1992, p.108109).
\end{abstract}

Autores diversos apontam desafios das reservas extrativistas, tais como: produção e conservação, turismo desordenado, qualidade de vida da comunidade local (OLIVEIRA, 2012; RISSO, 2012; FALCÃO, 2013; ALVITE et al., 2014; LOBATO et al., 2014; BRASIL, 2018; HAMOY, 2018). Apesar das dificuldades as RESEX federais correspondem a cerca de $20 \%$ das categorias de UC, no entanto somente 8\% em área (ICMBIO, 2019).

Sendo a RESEX Marinha de Soure (RESEXMS) a primeira no Pará, que apresenta dois biomas principais (Amazônico e Costeiros: restinga e mangue) tendo o turismo voltado ao turismo de sol e praia e ao ecoturismo, sendo o TBC buscado como desenvolvimento sustentável.

Neste sentido, buscou-se no presente estudo captar os diferentes olhares do TBC por protagonistas da RESEXMS e elucidar observações de estágio voluntário na UC.

\title{
Materiais e métodos
}

A pesquisa considerou o método qualitativo em Turismo, de cunho exploratório e descritiva (DENCKER, 2007), bem como estudo de caso (YIN, 2015) e observação participante (BECKER, 1999), ao longo de duas etapas: de gabinete e de campo.

Na primeira etapa houve: revisão de literatura; licença de pesquisa ํㅡㄴ 65514 , concedida pelo SISBIO/ICMBIO em 14/12/2018; elaboração de instrumento de coleta de dados; transcrição e tabulação das entrevistas por meio dos programas Windows 10 Microsoft Office e Excel respectivamente; geração de quadros e gráficos; e interpretação e discussão dos resultados.

$\mathrm{O}$ instrumento de coleta de dados foi um questionário semiestruturado qualitativo construído de acordo com a estratificação da amostra (Tabela 1). As questões foram selecionadas de forma a identificar características de cada públicoalvo para que houvesse interseções entre temáticas para comparação. 
Tabela 1: Questões-chave do questionário a respeito do TBC na RESEXMS.

Table 1: Key questions of the RESEXMS CBT questionnaire

\begin{tabular}{|c|c|c|c|c|}
\hline \multirow[b]{2}{*}{ Número } & \multicolumn{4}{|c|}{ Questões-chave } \\
\hline & Visitante & Comunidade & Gestor & Empresários \\
\hline 1 & Procedência & Conhecimento TBC & Conhecimento TBC & Conhecimento TBC \\
\hline 2 & Permanência & Definição TBC & Definição TBC & Definição TBC \\
\hline 3 & Motivação & $\begin{array}{c}\text { Recepção turistas } \\
\text { RESEX }\end{array}$ & TBC na RESEX & $\begin{array}{c}\text { Atividades TBC } \\
\text { RESEX }\end{array}$ \\
\hline 4 & Atrativos & Turismo impacta & Exemplos & $\begin{array}{c}\text { Recepção turistas } \\
\text { RESEX }\end{array}$ \\
\hline 5 & Turismo impacta & $\begin{array}{l}\text { Turismo RESEX } \\
\text { impacta }\end{array}$ & Dificuldades TBC & $\begin{array}{c}\text { Turismo } \\
\text { impacta/Impactos } \\
\text { turismo }\end{array}$ \\
\hline 6 & Impactos turismo & Impactos turismo & Turismo impacta & $\begin{array}{c}\text { Consciência } \\
\text { ambiental empresa }\end{array}$ \\
\hline 7 & Conhecimento TBC & $\begin{array}{c}\text { Mudanças turismo } \\
\text { Soure }\end{array}$ & Impactos turismo & $\begin{array}{c}\text { Reuniões turismo } \\
\text { Soure }\end{array}$ \\
\hline 8 & Definição TBC & $\begin{array}{l}\text { Organização } \\
\text { comunidade }\end{array}$ & $\begin{array}{c}\text { Relação RESEX } \\
\text { usuários }\end{array}$ & $\begin{array}{c}\text { Relação empresa } \\
\text { turismo Soure }\end{array}$ \\
\hline 9 & $\begin{array}{c}\text { Inserção } \\
\text { comunidade turismo }\end{array}$ & $\begin{array}{l}\text { Reunião Conselho } \\
\text { Deliberativo RESEX }\end{array}$ & $\begin{array}{c}\text { Relação } \\
\text { comunidade com } \\
\text { turismo }\end{array}$ & $\begin{array}{l}\text { Organização } \\
\text { comunidade }\end{array}$ \\
\hline 10 & $\begin{array}{c}\text { Serviços } \\
\text { comunidade em } \\
\text { viagens } \\
\end{array}$ & - & - & $\begin{array}{c}\text { Contribuição ICMBIO } \\
\text { para Soure }\end{array}$ \\
\hline 11 & Turismo em Soure & - & - & - \\
\hline 12 & $\begin{array}{l}\text { Guiamento turístico } \\
\text { pela comunidade }\end{array}$ & - & - & - \\
\hline
\end{tabular}

Fonte: dados da pesquisa (2019).

Source: research data (2019).

A etapa de trabalho de campo se deu em dois momentos distintos. Inicialmente estágio voluntário realizado pelo primeiro autor na RESEXMS entre 21/10/2017 e 15/01/2018, com reconhecimento de acessos e atrativos da UC e registro fotográfico; e por fim, trabalho de campo entre 10-13/03/2019, com aplicação de entrevista domiciliar a amostra de 16 entrevistados, sendo: 5 visitantes (5 turistas/excursionistas), 5 da comunidade, 1 gestor e 5 empresários. A amostra selecionada considerou stakeholders, parte dos conselheiros em reunião do Conselho Deliberativo da RESEXMS, composto por 16 representantes, sendo: 6 do poder público, 4 do setor privado e 6 da sociedade civil organizada (MMA, 2003; 2017).

\section{Estado da Arte}

O turismo pode ser considerado um bônus ou um ônus. Dentre aqueles destaca-se a esfera econômica, e desses a socioambiental. A balança com ambos pesos definirá sua sustentabilidade (SWARBROOKE, 2000).

A história do Turismo de Base Comunitária está relacionada ao Turismo Responsável, que para WWF (2003) é "Turismo realizado em áreas naturais, determinado e controlado pelas comunidades locais, que gera benefícios predominantemente para estas e para as áreas relevantes para a conservação da biodiversidade". 
Afim de integrar a questão sociocultural e sustentabilidade o TBC se insere como um campo advindo do turismo que tenta inserir a população e sua cultura a determinado ambiente, afim de alavancar não apenas economicamente, mas como ferramenta que valorize e conserve os saberes e conhecimentos, empoderando toda uma comunidade em torno do desenvolvimento do turismo local (BARTHOLO et al., 2009).

Para LTDS (2011, p. 2) "não há uma única definição conceitual específica amplamente aceita que defina o TBC, ainda que demonstrem similaridades de princípios". De acordo com MTUR (2010) o TBC envolve princípios, tais como: "autogestão; associativismo e cooperativismo; democratização de oportunidades e benefícios; centralidade da colaboração, parceria e participação; valorização da cultura local; e protagonismo das comunidades locais na gestão da atividade e/ou na oferta de bens e serviços turísticos, visando à apropriação por parte destas dos benefícios advindos do desenvolvimento da atividade turística".

Fabrino et al. (2016) ratificam esses princípios através dos aspectos: dominialidade; organização comunitária; democratização de oportunidades e repartição de benefícios; integração econômica; interculturalidade; e qualidade ambiental.

No Brasil as primeiras experiências - de iniciativa privada - remontam à década de 1990, concomitantemente às discussões ambientalistas da Rio-92. E se consolidaram com a inclusão do segmento no Plano Nacional de Turismo 20072010.

\begin{abstract}
o modelo de desenvolvimento proposto pelo governo contempla e harmoniza a força e o crescimento do mercado com a distribuição de renda e a redução das desigualdades, integrando soluções nos campos econômicos, social, político, cultural e ambiental. (...) o turismo pode ser uma importante ferramenta para o alcance dos Objetivos de Desenvolvimento do Milênio, particularmente com relação à erradicação da extrema pobreza e da fome, à garantia de sustentabilidade ambiental e ao estabelecimento de uma parceria mundial para o desenvolvimento (MTUR, 2007, p. 15).
\end{abstract}

Coriolano e Lima (2003, p. 41) correlacionam o TBC com o turismo que requer o envolvimento de todos, considera os direitos e deveres individuais e coletivos e elaboram um processo de planejamento participativo, desde as tomadas de decisões até a execução das atividades turísticas.

Para Brandão (2014) há o uso de Turismo de Base Local (TBL) como sinônimo, mas a autora aponta "que o que é local nem sempre é comunitário". Nessa linha Holanda (2016) aponta a empresarização do TBC, por meio de métodos científicos que usam termos empresariais para tratar o segmento, parcerias públicoprivadas (Sistema "S") e políticas públicas (MTUR), a exemplo dos "Arranjos Produtivos Locais". Para a autora (apud SAMPAIO et al., 2008) o conceito de "arranjo produtivo de base comunitária" (APL.Com) se apresenta com maiores possibilidades e de acordo com a essência do TBC.

$\mathrm{Na}$ sociedade do consumo o turismo também é produzido como espaço turístico. Krippendorf (2003) exemplifica o consumo das viagens como "desejo de fuga". A partir da urbanização há um "retorno à natureza" (fugere urben), o período do Grand Tour romantizou como consequência as áreas naturais na forma de 
proteção - desde os jardins botânicos do séc. XV ao Parque Nacional de Yellowstone, no XIX. Assim, a concepção de área protegida durante longo período destituiu as comunidades tradicionais de seu território por um lado, e estimulou o uso público por outro (TAKAHASHI, 2004).

Como destaque de uso público nas áreas naturais, o turismo - em especial o ecoturismo - é incentivado por organismos internacionais como a Organização Mundial do Turismo (OMT) e a União Internacional para a Conservação da Natureza (IUCN), a exemplo de 2017, comemorado como Ano Internacional do Turismo Sustentável.

O desenvolvimento de um modelo turístico sustentável, considera a cultura e o modo de vida local como as principais motivações para a viagem, sendo assim o turismo uma atividade complementar às atividades tradicionais desenvolvidas localmente (CORIOLANO, 2009).

Assim, iniciativas de empresas privadas - e posteriormente do setor público deram início ao desenvolvimento do TBC, principalmente em áreas rurais e naturais, com maiores impactos social (e.g. êxodo rural e insegurança alimentar) e ambientais (e.g. extrativismo desordenado) respectivamente.

Somam-se organizações não-governamentais (ONGs) ambientalistas, que passaram a encorajar as comunidades a receber turistas em seus espaços de moradia e trabalho, como viabilidade financeira e conservacionista. Apresentando assim o vínculo a movimentos sociais, para além da gestão participativa, mas pela comunidade, para preservação do patrimônio cultural e natural.

Visto dessa perspectiva, o TBC é baseado na autogestão sustentável dos recursos patrimoniais comunitários, de acordo com as práticas de cooperação e equidade no trabalho e na distribuição dos benefícios gerados pela prestação dos serviços turísticos. Experiência diferencial de TBC por incentivar o diálogo entre iguais e promover encontros interculturais, entre visitantes e visitados, tendo a perspectiva de que se conheça e aprenda com os modos de vida locais.

Como se pôde observar, o TBC é uma ferramenta que proporciona a integração entre a comunidade, com base na autogestão e participação deles. Sendo assim, é necessário que miremos o olhar para outras vertentes que possuem afinidade ao TBC, como as RESEX.

\section{A RESEX de Soure}

O conceito de RESEX remonta à década de 1980, quando seringueiros buscavam uma reforma agrária para os moradores da floresta. Sua primeira definição é do Decreto n.98.897 (BRASIL, 1990): "espaços territoriais destinados à exploração autossustentável e conservação dos recursos naturais renováveis por população extrativista". Com a Lei do SNUC passa a ser definida como

uma área utilizada por populações extrativistas tradicionais, cuja subsistência baseia-se no extrativismo e, complementarmente, na agricultura de subsistência e na criação de animais de pequeno porte, e tem como objetivos básicos proteger os meios de vida e a cultura dessas populações, e assegurar o uso sustentável dos recursos naturais da unidade (BRASIL, 2000, sd). 
Becker (2004, p. 107) observa que a criação das RESEX foi "fruto da luta dos seringueiros por sua sobrevivência na floresta, contra a expansão dos fazendeiros de gado e os projetos de colonização do INCRA". Projeto este, estruturado a partir de toda uma base, onde a organização e pressão permitiram que as primeiras Reservas Extrativistas fossem criadas em 1989, no estado do Acre, sendo elas legitimadas e reconhecidas de forma oficial pelo governo, através do SNUC. Representando um importante avanço quanto à concepção das áreas nacionais protegidas, incorporando objetivos de conservação e ações que promulgassem a inclusão social e econômica das populações diretamente ligadas. Modelo este que contribuiu de forma efetiva na redução de um dos principais problemas enfrentados, os conflitos fundiários.

A RESEXMS (Figura 1, próxima página), seguiu a passagem deste tipo de categoria de UC, onde a demanda por sua criação se dá através dos povos e comunidades tradicionais que habitam a região. O movimento surgiu com relação aos extrativistas e pescadores em geral, com maior destaque aos caranguejeiros (Figura 2, página 162), onde teve início no final dos anos 1990 a partir de uma preocupação surgida mediante os impactos causados por pesca predatória, praticada por "invasores" advindos principalmente do litoral do Pará, na região costeira de Soure/PA. Tal demanda ganhou assim força, incorporando aliados importantes, tanto os não-governamentais, quanto órgãos governamentais, como o Conselho Nacional das Populações Extrativistas (CNS) e o Centro Nacional de Pesquisa e Conservação da Sociobiodiversidade Associada a Povos e Comunidades Tradicionais (CNPT).

Sendo assim a RESEX foi criada em 2001. Localizada na costa leste da llha do Marajó é a maior ilha fluviomarinha do mundo, no estuário da Bacia Amazônica (BRASIL, 2018). Se estende por uma área de 27.463,58 hectares e $90 \mathrm{Km}$ de litoral, e abriga uma grande biodiversidade faunística e florística. Seus limites consideraram a garantia aos extrativistas locais das principais áreas de pesca, ou seja, "praticamente a totalidade das áreas de manguezais e suas praias e águas adjacentes (até uma milha náutica em águas abertas)" (idem).

A área é considerada a maior faixa contínua de manguezal do mundo (de MA a AP) de importância estratégica para a conservação, com presença da maior população ligada a pesca artesanal marinha costeira de todo o Brasil (idem). Associando-se, assim, a criação e manejo de UC da categoria RESEX e abrangência "Marinhas" na costa amazônica: 13 federais, sendo a de Soure a primeira da região, em um total de 90 RESEX, sendo estas 66 federais, em todo território brasileiro (idem).

Ainda de acordo com o Plano de Manejo da RESEXMS (idem) a biodiversidade e a geodiversidade são caracterizadas por exuberantes florestas de manguezais, com suas dunas intocadas, uma complexa rede de canais de maré, rios e igarapés de água doce e salgada interligados, além de campos alagados e matas, sendo berçário das mais diversas espécies - destaque para o peixe boi marinho (Tichechus manatus) e o amazônico (Trichechus inunguis), auxiliando no sequestro do carbono, proteção contra erosão costeira e a ciclagem de nutrientes.

Há pouco povoamento em parte da RESEX - categoria de uso sustentável que permite a propriedade particular -, em parte devido à dificuldade de acesso. $\mathrm{O}$ que repercute em praias selvagens e manguezais exuberantes (e.g., árvores com mais de $40 \mathrm{~m}$ de altura, constituindo as mais altas florestas de manguezal do mundo. 


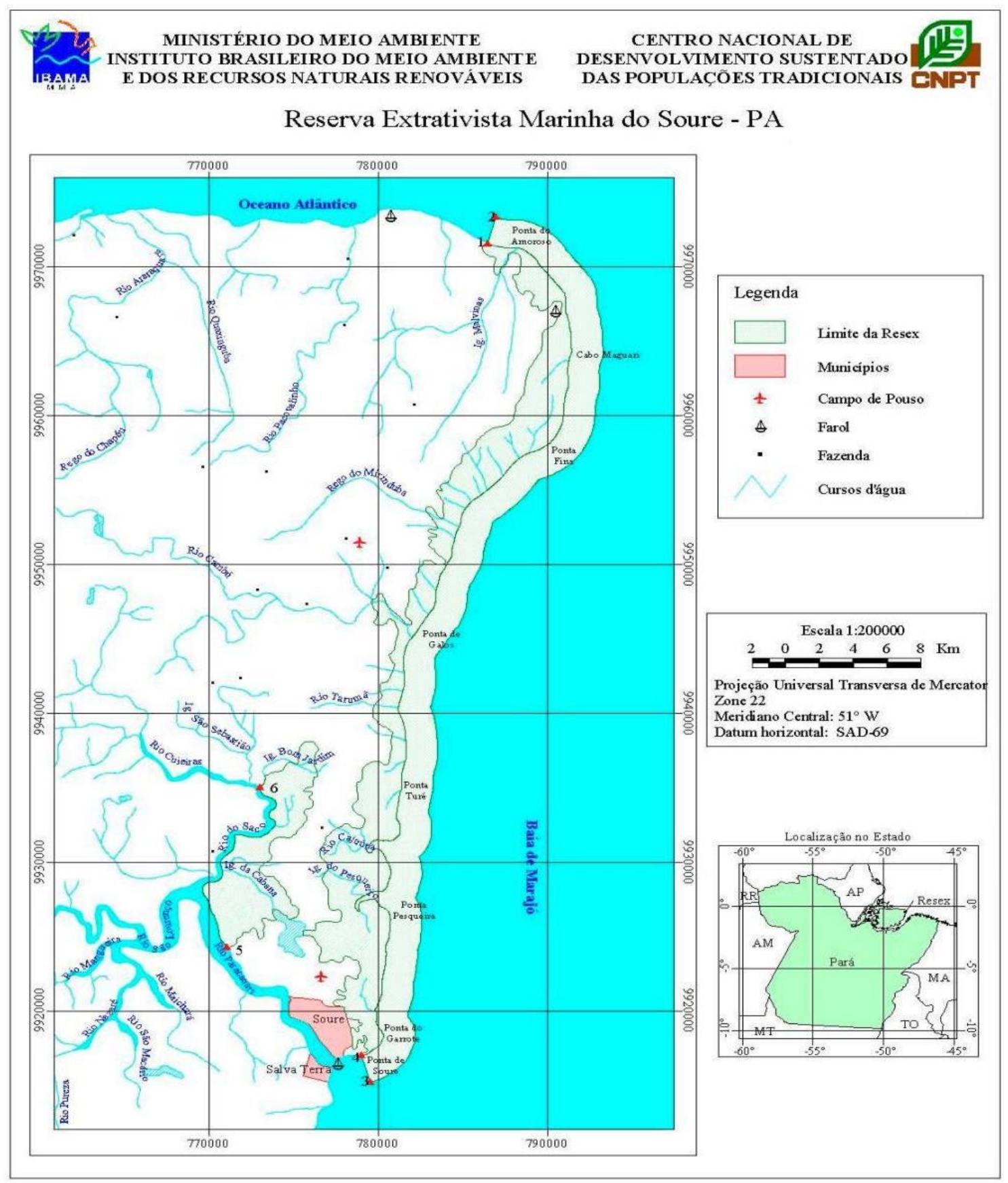

Figura 1: mapa de localização e acesso da RESEX Marinha de Soure/PA.

Fonte: modificado de Oliveira (2012).

Figure 1: location and access of National Marine RESEX of Soure, PA, Brazil.

Source: modified from Oliveira (2012).

Quanto às populações tradicionais a RESEX possuía em 20181.298 famílias extrativistas em comunidades no interior da UC (Araruna, Barra Velha, Pesqueiro, Céu, Caju-úna e Pedral) e em nove bairros urbanos fora dos limites da UC (Centro, São Pedro, Matinha, Umirizal, Pacoval, Macaxeira, Bom Futuro, Bairro Novo e Tucumanduba), totalizando $2 / 3$ destas famílias urbanas, na adjacência da unidade. As famílias têm nos recursos pesqueiros (peixes, caranguejo-uçá, camarões, siris, mariscos em geral) sua fonte de renda primária e nos recursos florestais não madeireiros (óleos naturais e frutos, por exemplo, açaí e o coco) a secundária (BRASIL, 2018). 

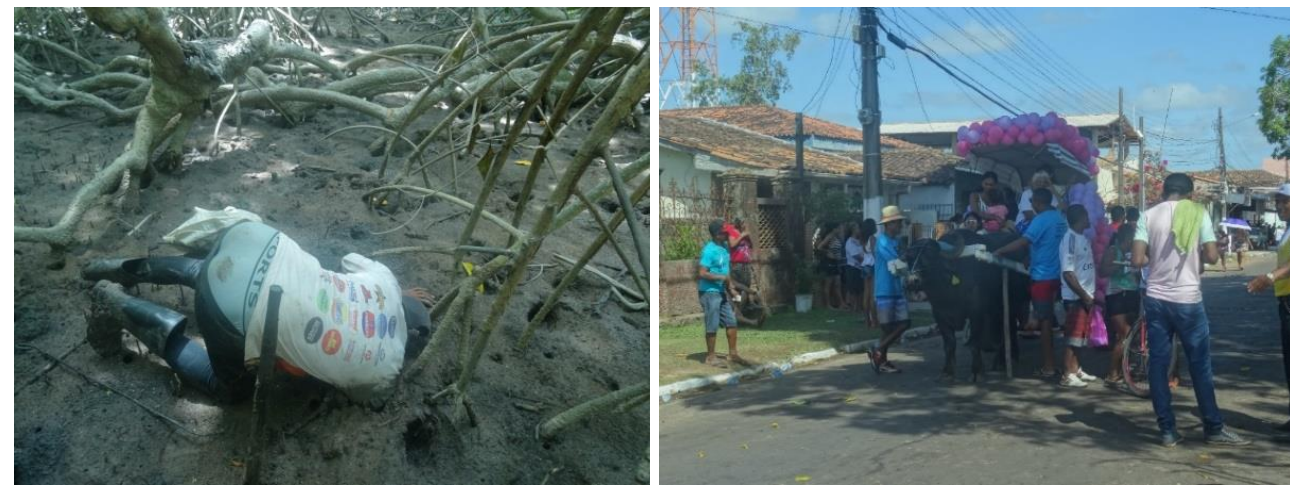

Figura 2: A) cata do caranguejo em bioma mangue; e B) Círio de Nazaré na RESEX Marinha de Soure/PA. Fonte: Jônatas Bastos (2018).

Figure 2: A) crab cage in mangrove biome; and B) Círio de Nazaré in the National Marine RESEX of Soure, PA, Brazil. Source: Jônatas Bastos (2018).

Assim pode-se identificar alguns itens, pertencentes a população que são ferramentas culturais já enraizadas que devem ser preservadas, a exemplo da cultura Marajoara, proveniente dos índios Aruãs e Maruanases, sofrendo também influência das culturas africanas e europeia, sendo resguardada pelos mais antigos e repassada ao longo das gerações, se expressando nas mais diversas práticas, sejam elas na gastronomia, a pesca artesanal, ritmos e danças, tal como o carimbó, lundu e boi marajoara. Através da cerâmica e sua linguagem iconográfica; medicina tradicional com seus óleos e ervas; práticas religiosas e místicas representadas por seus ritos, festividades e lendas locais.

Desta forma, as diversas práticas tradicionais quanto ao uso de recursos, contribuem de certa forma para a sustentabilidade e segurança alimentar de todas as comunidades presentes no território de Soure, contribuindo para a geração de renda das comunidades.

Como pudemos ver, a interação rica entre a Amazônia e o mar, promove assim um mosaico sublime de ambientes por toda reserva, com presença singulares de todo tipo de espécies na região, criando um ambiente favorável a prática do turismo ecológico e de base comunitária. E localizando-se a cerca de $80 \mathrm{~km}$ de Belém e de acesso fácil, a RESEX é assim constituída de grande riqueza cultural, incluindo os saberes locais e o modo de vida da população tradicional, configurandose como um atrativo a parte, acrescentada assim a um cenário paradisíaco, permeando um revigorante contato com a natureza amazônica marajoara.

\section{Diferentes olhares da RESEX}

A RESEXMS proporciona a integração do homem ao ambiente, a partir do uso sustentável dos recursos naturais do mangue, estuário, campos e várzeas. Promovendo a visitação sustentável onde a biodiversidade, os saberes e cultural local são os principais atrativos. Pode-se destacar ainda em Soure a imersão no sentimento de pertencimento a cultura marajoara, que é expressada através dos saberes e sabores, também na cerâmica e no carimbó (dança típica do Pará), inspirando uma relação harmônica com a natureza.

Além dos cenários que compõe a imagem do local é necessário que seja destacado ainda como parte do turismo e pertencente a Soure, os seguintes retratos identificados com ligação à RESEXMS (Quadro 1). 
Quadro 1: Retratos da RESEXMS

Chart 1: Portraits of the RESEXMS

\begin{tabular}{|c|c|}
\hline Retratos & Explicação \\
\hline $\begin{array}{l}\text { Significado do } \\
\text { nome Marajó: } \\
\text { "barreira do mar", } \\
\text { no idioma dos } \\
\text { índios que a } \\
\text { habitaram }\end{array}$ & $\begin{array}{l}\text { A ilha está localizada onde grandes Rios da bacia Amazônica encontram o mar, } \\
\text { tendo ora maior influência do grande volume de água doce vinda dos rios, ora } \\
\text { maior influência da água salgada do mar, de acordo com a época do ano. } \\
\text { Movimento este que influencia diretamente nas espécies entre os ambientes de } \\
\text { água doce e salgada ao longo da costa paraense e entre os dois hemisférios } \\
\text { formando na RESEXMS o ponto de encontro de uma rica diversidade de } \\
\text { ecossistemas e de espécies animais e vegetais típicas do local. }\end{array}$ \\
\hline $\begin{array}{l}\text { As características } \\
\text { ambientais da } \\
\text { RESEXmar } \\
\text { Soure }\end{array}$ & $\begin{array}{l}\text { Permitem a diferentes espécies encontrarem local favorável familiar e protegido } \\
\text { para sua reprodução, desenvolvimento e descanso. Dentre esses indivíduos, } \\
\text { várias espécies ameaçadas de extinção residentes ou migratórias encontram na } \\
\text { costa marajoara seu refúgio. }\end{array}$ \\
\hline $\begin{array}{l}\text { O uso dos } \\
\text { recursos naturais } \\
\text { da RESEX }\end{array}$ & $\begin{array}{l}\text { Realizado de forma sustentável, como o caso do Turu. Onde existem muitas } \\
\text { árvores de mangue caídas na praia, mas não se pode retirar, pois é de onde } \\
\text { nasce o turu. Que serve de alimento, de remédio e é considerado afrodisíaco por } \\
\text { muitos. }\end{array}$ \\
\hline $\begin{array}{l}\text { A tradicional } \\
\text { pesca } \\
\text { característica da } \\
\text { região }\end{array}$ & $\begin{array}{l}\text { A pescaria de "rabiola" na qual uma rede é presa em uma "vara de pau" apenas } \\
\text { de um lado. O outro lado da rede fica solto, "indo e voltando" com a força da } \\
\text { maré. Como esse movimento parece a soltura de uma rabiola ou pipa, a arte de } \\
\text { pescar ganhou esse nome. }\end{array}$ \\
\hline $\begin{array}{l}\text { A cerâmica e a } \\
\text { história de } \\
\text { ocupação de } \\
\text { Soure }\end{array}$ & $\begin{array}{l}\text { A cerâmica antiga conta a história da ocupação da região com vestígios } \\
\text { indígenas marajoaras de cerca de } 3.400 \text { anos atrás, que resistiram à ocupação } \\
\text { da região até a chegada dos jesuítas. Atualmente a cerâmica marajoara de Soure } \\
\text { mantém a conexão com a ancestralidade e expressa a identidade local pela } \\
\text { autenticidade de suas peças. }\end{array}$ \\
\hline $\begin{array}{l}\text { Práticas } \\
\text { religiosas e } \\
\text { místicas }\end{array}$ & $\begin{array}{l}\text { Diversidade de cultos - catolicismo (como o Círio), benzedeiras, evangélicos e } \\
\text { religiões de terreiro (umbanda, tambor de mina e pajelança) com suas } \\
\text { festividades, ritos, comidas típicas, óleos e essências. Garantidos pela } \\
\text { organização e comprometimento das comunidades e que transmitem união, } \\
\text { conexão com a natureza, acolhimento, sentimento de proteção e vida espiritual. }\end{array}$ \\
\hline Ritmos e danças & $\begin{array}{l}\text { olvem instrumentos musicais peculiares e tradicionais fabricados em grande } \\
\text { e com materiais da natureza. Incluem o uso de vestimentas particulares do } \\
\text { mbó e lundu, que são confeccionadas com chita estampada, chapéu de palha } \\
\text { tros adereços, transmitindo alegria, emoção uma forma de se conectar com a } \\
\text { tidade cultural marajoara. }\end{array}$ \\
\hline $\begin{array}{l}\text { O "nasc } \\
\text { da RES }\end{array}$ & $\begin{array}{l}\text { descontentamento da comunidade com a devastação dos recursos naturais e } \\
\text { ércia dos órgãos públicos nasceu o "Manifesto Caranguejeiro", da Associação } \\
\text { Caranguejeiros de Soure. A partir deste evento as comunidades de Soure e } \\
\text { umas entidades públicas locais passaram a fomentar a ideia de criar uma } \\
\text { dade de conservação, surgindo, então, a reserva, agregando três } \\
\text { nunidades de pescadores e catadores de caranguejo. }\end{array}$ \\
\hline $\begin{array}{l}\text { Povos e } \\
\text { paisagens das } \\
\text { marés }\end{array}$ & $\begin{array}{l}\text { A força das marés e dos ventos é de adaptação e deslocamento. Até já dividiu } \\
\text { vila. É o caso de Araruna. As praias são influenciadas pelas águas de rio e mar, } \\
\text { formando paisagens diferentes em cada época do ano, e junto com as forças das } \\
\text { águas, os ventos vão transformando as áreas das formações naturais existentes. } \\
\text { Onde as comunidades estão sempre se adaptando às mudanças. }\end{array}$ \\
\hline O manguezal & $\begin{array}{l}\text { Um dos ecossistemas mais produtivos do planeta. Contribui para a } \\
\text { biodiversidade de relevância mundial, assegura a integridade ambiental da faixa } \\
\text { costeira e fornece recursos e serviços ambientais que sustentam atividades } \\
\text { econômicas. Onde Soure está inserida na maior faixa contínua de manguezal do } \\
\text { mundo. }\end{array}$ \\
\hline Caranguejo-uçá & $\begin{array}{l}\text { É o grande consumidor das folhas de mangue. É o engenheiro do manguezal, } \\
\text { pois constrói galerias para se refugiar, causando o revolvimento dos estratos } \\
\text { sedimentares e seus nutrientes. Vive até dez anos e demora três anos para } \\
\text { crescer até chegar ao tamanho para ser consumido, representando grande fonte } \\
\text { de renda e alimento a população. }\end{array}$ \\
\hline
\end{tabular}

Fonte: dados da pesquisa (2019).

Source: research data (2019). 
Possuindo, assim, um ambiente favorável para a prática do turismo ecológico e de base comunitária, pois conta já com uma rica história data de alguns milênios com a arte marajoara, além de um componente da rica biodiversidade muito rico. Sendo assim necessário que sejam identificados nas atuais condições os pontoschaves a serem coordenados.

Sendo assim, também é necessário identificar os pontos falhos a serem corrigidos, como um maior envolvimento comunitário, a fim de que o conceito de TBC esteja implementado mais fortemente, ocorrendo assim um planejamento afim de que todo potencial seja verdadeiramente utilizado, atendendo a população como um todo, visando o crescimento da comunidade de Soure.

Quanto ao conhecimento a respeito do TBC observa-se que os entrevistados que moram/trabalham em Soure sabem o que é, enquanto nenhum visitante sabe ou quis responder (Figura $3 \mathrm{~A}$ ). Por sua vez ao serem questionados quanto à definição de TBC todos que responderam que sabem o que é TBC associaram o conceito à "comunidade", com variação da importância ao "turismo" (2 respostas), seguida de "protagonista", "ação" e "trabalho" (1 resposta cada) (Figura 3B).

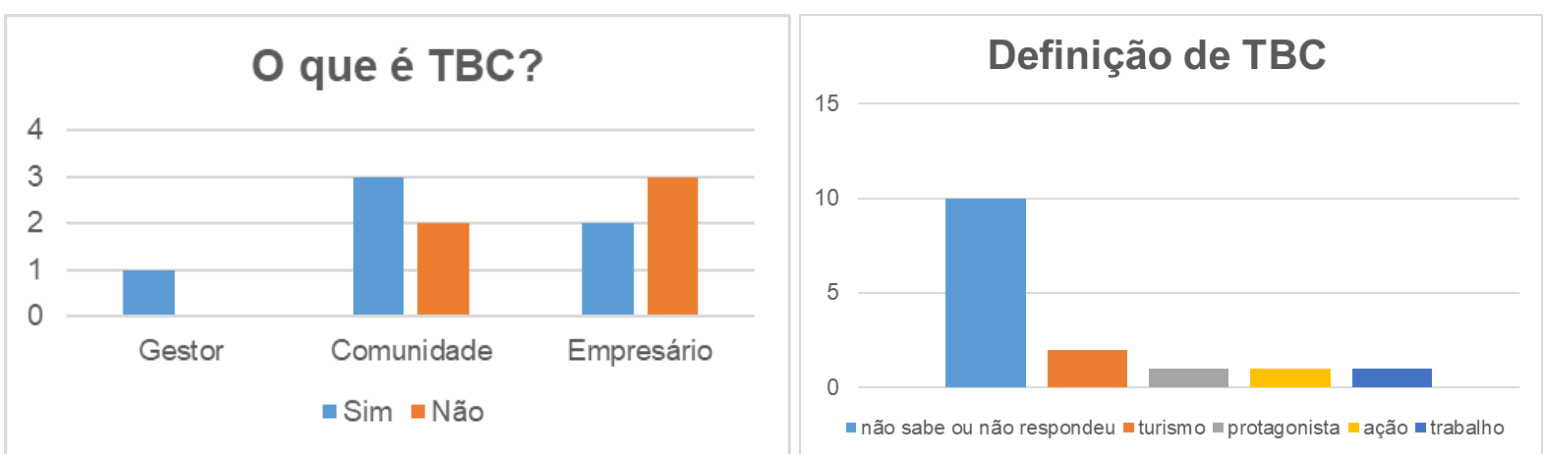

Figuras 3: gráficos a respeito de A) TBC; e B) definição de TBC pelos entrevistados na RESEX Marinha de Soure/PA. Fonte: dados da pesquisa (2019).

Figure 3: graphic about A) TBC; and B) definition of TBC to those interviewed in the Marine RESEX of Soure, PA, Brazil. Source: research data (2019).

Percebe-se, assim, que há uma relação diretamente proporcional à inserção da comunidade no TBC $(60 \%$ conhece o termo e define a comunidade como protagonista), e inversamente proporcional dos empresários (40\% conhece o termo correlacionou à turismo e trabalho) e turistas (nenhum conhece e definiu).

\section{Olhar do Gestor}

Para o chefe da RESEX o TBC é o tipo de turismo que a comunidade é a protagonista, com respeito à sua cultura, seus valores, seu modo de vida. Ele considera que pode ser mais bem desenvolvido com a captação de recursos pela UC, tais como: financeiros (para projetos de monitoramento), materiais (combustível e manutenção de veículos) e humanos (aumento da equipe).

Com relação à existência do TBC na Reserva o gestor alegou que existem sim algumas iniciativas, no entanto do setor privado e da sociedade civil organizada:

Associação pesqueira de mulheres, restaurante e pousada comunitária Céu. (Entrevistado Gestor) 
Onde já vem sendo trabalhado princípios do TBC, ainda em pequena escala. $E$ que a maior dificuldade enfrentada para um melhor desenvolvimento do TBC seria "aplicação do coletivo", demonstrando que ainda possuem alguns percalços a serem percorridos para uma melhor aplicação do TBC.

A respeito da relação da RESEX com os demais, sejam turistas, empresários e a comunidade em geral:

Turistas não possui, comunidade via conselho, empresários sendo trabalhado. (Entrevistado Gestor)

Uma relação quanto aos visitantes que talvez demonstre ainda uma defasagem, já que o diálogo com os turistas acaba sendo nulo, o que prejudica que se tenha uma maior visão do que procuram os turistas que vêm a Soure, quais pontos podem e devem ser trabalhados para que sejam atendidos, garantindo um aproveitamento maior da cidade em si.

Quanto ao desenvolvimento do turismo e a resposta da comunidade para tal, além das inquietações dela, foi colocado que:

Turismo ainda desordenado, variável entre comunidades (Entrevistado Gestor)

Onde é visto que ainda não existe uma base sólida para o turismo, o qual vem sendo trabalhado, acabando por gerar as variáveis entre as comunidades quanto ao fluxo de turistas recebidos.

\section{Olhares da Comunidade}

As entrevistas com a comunidade demonstraram certa diferença do gestor, paradoxo na efetividade de gestão de uma categoria de UC e segmento turístico que é prioritário aos recursos extrativistas e à comunidade que sobrevive dos mesmos.

Quanto ao recebimento de turistas, foi unânime que é sim benéfico o recebimento destes, divergindo quanto ao ponto positivo apenas em uma resposta, que apontou a conservação como um ponto positivo, enquanto os demais apontaram a questão financeira.

Quanto aos tipos de impactos positivos gerados pelo turismo, $80 \%$ dos entrevistados indicou a questão econômica como maior ponto positivo, enquanto somente $20 \%$ indicou a questão de identidade cultural como melhor, o que ratifica a fala do gestor.

Quanto a pontos negativos $40 \%$ indicou que a questão de um turismo desordenado é o que mais prejudica, enquanto $60 \%$ indicou outras questões como mais prejudicial, como o não respeito com o lugar e a falta de água (nos meses de seca, que vão de agosto a janeiro), marcando também uma alta temporada, gerando maior uso dos recursos hídricos, conforme relatos: 
Melhora na economia, não respeito ao lugar (Entrevistado Comunidade 1)

Financeiramente, falta de água (Entrevistado Comunidade 5)

A maioria $(60 \%)$ da comunidade entrevistada acredita que as mudanças ocorridas por conta do turismo foram positivas, enquanto $60 \%$ acredita que não exista uma organização entre as comunidades quanto ao desenvolvimento do TBC, em acordo com a argumentação do gestor, quando diz que "possuem algumas iniciativas, porém não uma rede completa e interligada entre todos". Quanto à participação em reuniões da UC a maioria dos entrevistados já participou ao menos uma vez de reunião da RESEXMS.

\section{Olhares dos Empresários}

O tipo de trabalho exercido pelos entrevistados do setor privado há um compartilhamento entre artesanato (40\%), seguido de hospedagem, produtos naturais e alimentação ( $20 \%$ cada). Quanto aos aspectos positivos de receber turistas, todas respostas tiveram enfoque na questão financeira:

\section{Movimenta economia (Entrevistado empresário 1).}

Renda (Entrevistado empresário 4).

Podemos enxergar mais claramente os aspectos positivos e negativos citados pelos empresários entrevistados quanto aos impactos gerados pelo turismo, onde podemos notar que novamente a questão econômica se destaca, enquanto a questão do fluxo de pessoas pode-se ver que foi citada tanto para o lado negativo quanto positivo.

Economia, mal-uso da cidade (Entrevistado empresário 1).

Preocupação com a reserva, fluxo grande (Entrevistado empresário 2).

Todos os empresários entrevistados, disseram que a empresa se preocupa quanto a preservação cultural e ambiental da cidade:

Utilização de produtos locais (Entrevistado empresário 1).

Eventos culturais (Entrevistado empresário 3).

Valorizando saberes locais (Entrevistado empresário 5).

No entanto, a maioria dos entrevistados (60\%) não participa ou nunca participou de algum tipo de reunião quanto ao desenvolvimento do turismo, consolidando a dificuldade na gestão participativa e consequentemente efetividade de gestão. As respostas quanto ao papel representado pelas empresas em questão no que tange o desenvolvimento do turismo, foram bem variadas, mostrando diversas possibilidades e entendimentos dos papeis por eles representados na cidade: 


\section{Divulgação da arte marajoara (Entrevistado empresário 2). Valorização do trabalho local (Entrevistado empresário 5).}

Os entrevistados demonstraram ainda preocupação com a questão da cultura e também da valorização do trabalho local, principalmente os que estão diretamente ligados aos saberes populares, como os envolvidos com a questão do artesanato e ervas e plantas medicinais, afinal é um conhecimento sobre plantas e seu preparo que infelizmente vem se perdendo pouco a pouco, sendo necessário seu fortalecimento e resgate.

Houve unanimidade quando perguntados a respeito da existência de uma organização entre as comunidades para o fortalecimento do turismo como um todo, sendo a resposta negativa. $\mathrm{O}$ que entra em contraste com algumas das respostas da comunidade, mas mostra que de fato a visão é de que não existe uma rede trabalhando em total cooperação.

Quando perguntados a respeito da contribuição da RESEXMS para o turismo na região, apenas uma resposta foi negativa, a exemplo da fala de um entrevistado diferente da dos demais, que acredita que a intervenção pode acabar atrapalhando o turismo.

As motivações que podem levar a visão de que a reserva pode vir a atrapalhar o turismo, talvez seja muito ligada à questão econômica, a mais citada como grande contribuição do turismo. As leis ambientais e um rigor quanto ao uso do espaço, como a prática de esportes aquáticos, como o kite surf, prática a qual atrai muitos turistas às águas de Soure, pode por sua vez ser prejudicial aos pescadores, sendo pauta da reunião em que participei do conselho. Desta forma são muitas as nuances a serem enxergadas quanto ao turismo em sua totalidade, de modo a não causar prejuízo seja a natureza ou a própria população.

\section{Olhares dos Visitantes}

Marajó é considerada um Polo de acordo com a Secretaria de Estado de Turismo do Pará (PARATUR, 2010). De acordo com a Paratur (2009) o município de Soure recebeu 22.039 turistas. Não foi encontrada pesquisa recente a nível federal (MTUR e ICMBIO), estadual (PARATURISMO, 2019) ${ }^{1}$ ou municipal (SOURE, 2019) ${ }^{2}$ perfil da demanda turística. No entanto, de acordo com o Plano de Manejo da UC (BRASIL, 2018, p. 37) a priorização da necessidade desses dados dos chamados "recursos e valores fundamentais (RFV)" é "baixa". De acordo com Hamoy (2018) não existe estudo atual de demanda, sendo que

O último estudo de demanda turística municipal foi realizado em 2012. A defasagem desse estudo implica no desconhecimento do fluxo atual de turistas que o município recebe e, por consequência, não se sabe o valor financeiro que os visitantes deixam, e de que modo o turismo como atividade econômica impacta em Soure. Somado a isso, inexistem estudos estatísticos que poderiam auxiliar no processo de planejamento (HAMOY, 2018, p. 125). 
Em 2013 o ICMBIO iniciou o projeto de ordenamento de uso público na UC "Praias de Soure: nosso paraíso Marajoara", no entanto sem divulgação do perfil da demanda turística, frequentemente citada como "massiva", "ameaça" (PINHEIRO et al., 2013) e "predatória" (LOBATO et al., 2014). Assim, embora a amostra foi somente de 5 pessoas, considera-se importante para a pesquisa, somando-se à estratificação complementar.

A partir dos questionários aplicados aos visitantes $80 \%$ é de turistas (permanecendo de 2 a 7 dias no município) e turismo doméstico (3 da região Nordeste e 1 da Norte). Isso "evidencia a possibilidade de intercâmbio intercultural, uma característica importante do TBC", segundo Alvite et al. (2014) citando Sansolo e Bursztyn (2009) e Fabrino et al. (2012).

Três dos cinco visitantes foi à Soure para conhecer pela primeira vez, enquanto o restante estava indo para visitar parentes. Os principais atrativos preferidos pelos visitantes relacionam-se ao segmento "turismo de sol e mar", exceto um relacionado a uma atividade do ecoturismo, a "observação de fauna":

\section{Baleia encalhada no Araruna (Entrevistado visitante 2).}

O que demonstra o potencial para observação dos maiores mamíferos marinhos e, indiretamente, de outras espécies advindas da rica fauna marinha do local como botos, peixe-boi, peixes e mariscos.

Todos os entrevistados acreditam que a comunidade de Soure está inserida no turismo da cidade, sendo que a maioria dos visitantes (80\%) opta pela utilização de serviços locais. Neste aspecto acreditam que falta em Soure:

Infraestrutura (Entrevistado visitante 1).

Atrações à noite (Entrevistado visitante 2).

Informação (Entrevistado visitante 3).

Complementarmente, quanto aos tipos de atrativos foram citados com relação ao turismo cultural e ao agenciamento/marketing turístico:

Apresentação cultural (Entrevistado visitante 1).

Roteiros de natureza (Entrevistado visitante 3).

Além dos questionários aplicados, as conversas e vivências enquanto voluntariado permitiram que fosse entendido um pouco melhor de como Soure é enxergado, o que a população crê e o que vem sendo feito como um todo, as incertezas e sonhos que vem sendo trabalhados. 


\section{Olhares ao Norte}

Como pode-se observar a partir das entrevistas aplicadas a diferentes pessoas, com diferentes olhares a respeito do turismo em Soure e das conversas durante o decorrer dos dias e vivências em Marajó. Percebe-se um novo olhar.

De que, embora ainda existam diversos pontos a serem trabalhados no turismo como um todo, existe certa divergência quanto a redes existentes entre as comunidades, o que pode ser destacado nas entrevistas, que mostraram respostas conflitantes quanto as iniciativas existentes entre as comunidades para 0 fortalecimento do turismo.

Onde é visto que embora exista a vontade para que o turismo se desenvolva é ainda algo muito embrionário, com alguns impasses. Existindo algumas poucas conexões já realizadas entre comunidades, mas não algo que envolva o todo. O que de certa forma acaba restringindo o turismo de Soure a um roteiro que envolve somente uma ou duas praias, enquanto fica de fora o potencial turístico de Soure e região.

O processo de crescimento econômico deve ser liderado por uma participação ativa da comunidade, envolvendo também os empresários locais que devem compreender e se enxergar como parte de toda a rede, se inserindo ativamente quanto à organização, pois quando algumas falhas são apontadas pelas entrevistas, estas devem ser revistas e desenvolvidas. Esse tipo de desenvolvimento caracteriza-se como uma forma de organização da produção, e de integração da sociedade e das instituições aos processos produtivos, e à capacidade de resposta do território ao cenário económico, político e institucional (FABEIRO, 2004).

A questão econômica, que de forma quase unânime foi citada por todos entrevistados como sendo maior ponto positivo do impacto do turismo em Soure é tratado já há mais tempo como uma ferramenta que pode e deve ser ampliada, mas que para isto exista um bom uso dos recursos existentes por todo território. Como salientou, Santos Júnior (2006): o uso sustentável de recursos disponíveis na área da reserva, incluindo o potencial turístico e pesqueiro pode gerar renda e consequente melhoria na qualidade de vida dos extrativistas.

Sendo desta forma o TBC, um dos principais agentes neste poder de transformação, quando bem aplicado poderá trazer ganhos a toda comunidade, 0 que demonstra a observação quanto ao turismo ocasionar impactos (Figura 4, próxima página).

Quanto ao tipo de impacto a grande maioria (73\%) dos entrevistados aponta os positivos como relacionados à economia, sendo uma resposta relacionada à conservação ambiental e outra ao patrimônio cultural. Os negativos por sua vez se compõem por turismo desordenado e resíduos ( $20 \%$ cada) seguido de falta de água (2 respostas) (Tabela 2 ). 


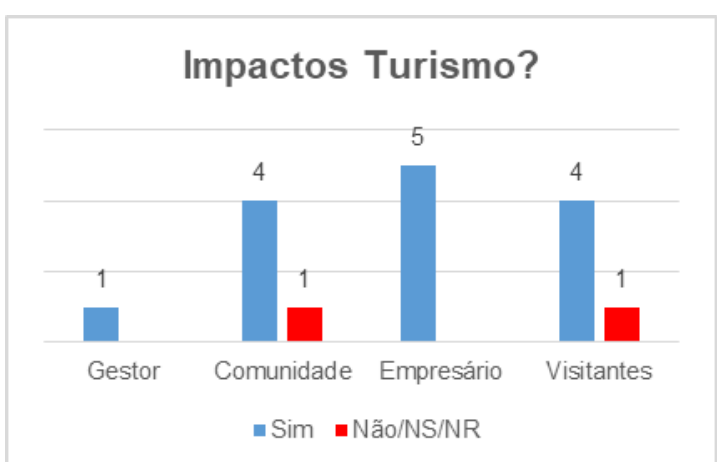

Figura 4: gráfico a respeito da percepção dos entrevistados se o turismo impacta na RESEX Marinha de Soure/PA. Fonte: dados da pesquisa (2019).

Figure 4: graph about respondents' perception of whether tourism impacts on the Marine RESEX of Soure, PA, Brazil. Source: research data (2019).

Tabela 2: Impactos do turismo na RESEXMS.

Table 2: Tourism impacts on the RESEXMS.

\begin{tabular}{|c|c|c|}
\hline Entrevistados & $\begin{array}{c}\text { Positivos } \\
\end{array}$ & Negativos \\
\hline Gestor & $\begin{array}{l}\text { Renda, cultura, identidade, } \\
\text { fortalecimento coletivo }\end{array}$ & $\begin{array}{c}\text { Desordenado, mazelas sociais, } \\
\text { descaracterização }\end{array}$ \\
\hline \multirow{5}{*}{ Comunidade } & Melhora economia & Não respeito ao lugar \\
\hline & Movimenta economia & Acomodado \\
\hline & Economia & Desordenado \\
\hline & Identidade comunidade & Desordenado \\
\hline & Financeiramente & Falta de água \\
\hline \multirow{5}{*}{ Empresários } & Economia & Mal uso da cidade \\
\hline & Preocupação reserva, fluxo grande & Falta de água \\
\hline & Depende & tidade \\
\hline & Movimenta a cidade & Sujeira \\
\hline & Economia & Nenhum \\
\hline \multirow{5}{*}{ Visitantes } & Economia & Sujeira \\
\hline & Economia & Sujeira \\
\hline & Economia & Nenhum \\
\hline & NS/NR & NS/NR \\
\hline & Economia & Nenhum \\
\hline
\end{tabular}

Do outro lado, um ponto citado como problema do impacto do turismo na cidade, foi a questão da poluição, principalmente o lixo deixado para trás pelos turistas. O que se torna um agravante pois de acordo com Oliveira (2012) a coleta seletiva só é realizada nas comunidades da Vila do Pesqueiro e Barra Velha em função de serem praias, ficando de fora as outras comunidades, inclusive a Comunidade do Caju-Úna, onde os moradores enterram ou queimam seu lixo doméstico.

Porém, é preciso salientar que dentre as respostas, pode-se destacar a da empresária E5, que diz: 
Geralmente quanto à sujeira, possuem mais respeito quanto à terra que os locais.

Mostrando uma visão, de que muitas vezes o problema do lixo acaba por ser algo mais interno do que externo. Cabendo assim medidas em esferas como a da educação (ambiental), onde o povo possa estar cuidando do lugar que lhes pertence e valorizando.

Também destacamos a questão das marés e a poluição no mar, que arrasta consigo toneladas de plástico, óleo e outros às praias quase desertas de Soure, onde uma vez na praia acabam por se prenderem as raízes das árvores dos manguezais e ficando por lá, contribuindo negativamente para a estética das praias. Um ambiente saudável promove a convergência dos objetivos básicos para conservação da biodiversidade em unidades de conservação, que diz respeito à proteção de paisagens (BASTOS; SANTOS, 2008).

Ao serem aplicados os questionários aos visitantes, ficou claro que novas experiências turísticas são válidas, roteiros que fujam do usual. Principalmente quanto ao interesse por atividades de cunho cultural, entre as 5 entrevistas feitas aos visitantes a parte cultural foi levantada como um aspecto de atividade de interesse do turista.

Como pode ser observado pelas respostas dos visitantes, V2, que já esteve em Soure outras vezes, que deu sua opinião quanto ao turismo em Soure e pontos a serem melhorados.

Poderia ser melhor. Recepção, carimbó que havia depois da ponte, música nas praias, atrações à noite quanto à cultura marajoara.

Demonstrando que o aspecto cultural é algo de suma importância quando se trata do turismo, principalmente de um local onde a cultura é representada principalmente pela arte marajoara. A própria recepção do turista pode ser observada na resposta, onde logo na chegada há um receptivo turístico de carimbó, dança típica do estado do Pará. Mostrando assim também, o quanto a noite em Marajó pode acabar não possuindo muitas opções de entretenimento para os turistas, deixando o turismo ligado apenas ao velho roteiro sol e mar, que é a grande motivação das visitas a Soure, como apontaram as entrevistas. Portanto, encontrar saídas e alternativas dentro deste modelo já consolidado tem uma importância ainda maior.

Destes aspectos que entravam o turismo em Soure, também pode-se citar a questão estrutural da própria cidade, onde a infraestrutura, ou falta dela, pois o acesso à llha do Marajó já é de certa forma complicado, o que foi citado por dois dos turistas entrevistados, V1 e V5, que destacaram este ponto como algo a ser melhorado na cidade.

Por outro lado, entre os turistas a entrevistada V2, citou que

Houve uma melhoria na infraestrutura durante os últimos anos. 
Então podemos observar que, embora possa ter melhorado o acesso, principalmente a partir da chegada da lancha que diminuiu consideravelmente o tempo de travessia para ir e vir de Belém.

Tal como é destacado pela entrevistada $\mathrm{C} 4$, respondendo quanto a mudanças observadas na cidade a partir do turismo:

Na cidade não, apenas foram fortalecidas algumas questões. Mudança no transporte a partir da lancha.

O acesso e circulação a mais pessoas ainda é um ponto que enfrenta impasses. Principalmente pela localização geográfica do Marajó, sendo uma ilha, os municípios ficam, de certa forma, isolados, tornando a circulação de pessoas mais difícil. São mudanças estas que de certa forma servirão para maior atratividade para o município e região.

O que nos remete a outro ponto tocado, de que o turismo em Soure possui suas nuances particulares quanto ao acesso a seus principais pontos turísticos, com o fluxo maior de turistas que fica reservado a praticamente duas praias, a do Pesqueiro e de Barra Velha. Onde a comunidade do Caju-una e do Céu acabam tendo seu acesso restrito devido a uma porteira com um vigia, localizada no caminho entre o centro de Soure e as comunidades.

Fluxo de turistas este que, como dito pelo gestor, possui ainda variáveis entre as diferentes comunidades. Mostrando que talvez seja reflexo da questão territorial que pode influenciar alguns empecilhos como a dificuldade do acesso, atrapalhando um maior desenvolvimento do turismo.

O que pode ser observado é de que existem sim pequenas iniciativas já sendo realizadas, porém alguns conflitos e falta de organização acabam por atravancar potencial, não sendo assim igualmente aplicadas. Porém, pensarmos na questão de comunidades sem pensarmos na questão de conflitos seria criar uma realidade utópica (BAUMAN, 2003). Já que a vida em sociedade apresenta suas contradições e dificuldades.

Quando enxergamos o TBC como uma tarefa em que a própria sociedade se envolver efetivamente na gestão e desenvolvimento do projeto de turismo desejados por eles.

No caso de Soure, esta conversa e envolvimento já existem e embora caminhe a passos lentos, o processo para construção de uma forte rede de TBC já foi iniciado. Reuniões onde a comunidade e empresários atuam junto à RESEXMS já existem e pouco a pouco medidas vão sendo traçadas para uma implementação de um turismo que abranja e funcione para todos, identificando os produtos existentes e os fortalecendo, para que os índices e metas sejam alcançados. 


\section{Considerações Finais}

Atender aos anseios básicos da população é algo imprescindível para que exista o sucesso na prática do TBC. Pois, é a partir dos saberes tradicionais dos povos, de seu conhecimento a respeito do lugar, tradições e diversidades existentes e vivenciadas pela comunidade que se dará a construção da rede de turismo. Desta forma, é necessário que a população local esteja em proximidade com as demais esferas de poder responsáveis pela gestão turística de Soure, como a própria RESEXMS e a prefeitura, procurando sanar quaisquer eventuais problemas enfrentados pela região.

A vasta cultura, seja ela com os tradicionais, ricos e detalhados artesanatos marajoaras e toda história de uma civilização que por ali viveu, ou os diversos pratos típicos, as mais diversas frutas, como o açaí, o murici, as mangueiras espalhadas por Soure, que durante os meses de outubro e novembro enriquecem ainda mais a cidade. A beleza do carimbó dançado em trajes típicos, a bela fauna, seja com os guarás, botos, entre outros animais como o próprio caranguejo-uçá, ou mesmo o búfalo que se tornou um marco de toda a ilha. Os imponentes manguezais que recobrem as praias quase desertas, trazendo um ar de liberdade, afinal de fato a ilha é uma porção de terra desprendida do restante do Brasil. Tudo isto compõe uma atmosfera única, muito rica e de extremo valor, marcos que devem ser valorizados por toda sua representatividade no território de Soure do próprio Marajó.

O potencial turístico, como foi visto, é enorme. Porém ainda é necessário que exista um trabalho de base maior, fortalecendo a população e dando a ela uma visão acerca de tudo que compõe sua vida, mostrando e valorizando tais condições, adquirindo assim uma maior autonomia e valorização de si próprio, uma auto estima que só tem a trazer benefícios de maneira geral. Precisando que exista assim um maior despertar como um todo, onde problemas internos devam ser deixados de lado para que consiga encontrar um viés de atuação como um todo, onde seja possível existir um crescimento que atenda a todos.

Podendo assim, utilizar verdadeiramente todo potencial existente no turismo do local. Para que assim, o TBC consiga ter uma atuação consistente, fortalecendo ainda mais as comunidades e valorizando cada diferente conhecimento existente, criando toda uma rede bem sustentada pelos autóctones e donos do local, onde a partir disto possam vivenciar ainda mais a própria vida em comunidade, coexistindo com um forte turismo.

\section{Agradecimentos}

Os autores agradecem à Universidade Federal de Ouro Preto pelo apoio; à Reserva Extrativista Marinha de Soure pelo estágio voluntário; aos conselheiros do Conselho Deliberativo da RESEX pelas entrevistas; ao Instituto Chico Mendes de Conservação da Biodiversidade pela licença de pesquisa; e aos pareceristas da Revista Brasileira de Ecoturismo pela revisão. 


\section{Referências}

ALVITE, C.M.C.; VIDAL, M.D.; BORREANI, O.H.P.; BORBA, E.C.M. Perfil da visitação na llha dos Lençóis, comunidade de pescadores tradicionais, Reserva Extrativista de Cururupu (MA). Revista Brasileira de Ecoturismo, v.7, n.4, p.656680, 2014.

BARTHOLO, R.S.; SANSOLO, D.G.; BUSZRTYN, I. Turismo de base comunitária: diversidade de olhares e experiências brasileiras. R. Janeiro: Letra e Imagem, 2009.

BASTOS, M.N.C.; SANTOS, J.U.M. Caracterização e composição florística de ecossistemas naturais In: JARDIM, M.A.G.; ZOGHBI, M.G.B. (org.). A flora da RESEX CHOCOARÉ- Mato Grosso (PA): diversidade e usos. Belém: MPEG, 2008.

BAUMAN, Z. Comunidade: a busca por segurança no mundo atual. Rio de Janeiro: Zahar, 2003.

BECKER, B.K. Amazônia: geopolítica na virada do III milênio. Rio de Janeiro: Ed. Garamond. 2004.

BECKER, H.S. Métodos e técnicas em pesquisa em ciências sociais. Trad. Marco Estevão e Renato Aguiar. São Paulo: Hucitec, 1999.

BRANDÃO, J.O.S. Turismo de Base Comunitária: ressignificando a concepção de comunidade. Dissertação (Mestrado em Turismo) - Centro de Excelência em Turismo, Universidade de Brasília - Brasília, 2014.

BRASIL. Decreto 98.897. Dispõe sobre as reservas extrativistas e dá outras providências. Brasília: Governo Federal, 1990.

BRASIL. Lei 9.985. Regulamenta o art. 225, § 10, incisos I, II, III e VII da Constituição Federal, institui o Sistema Nacional de Unidades de Conservação da Natureza e dá outras providências. Brasília: Governo Federal, 2000.

BRASIL. Plano de desenvolvimento territorial sustentável para o arquipélago do Marajó: resumo executivo da versão preliminar para discussão nas consultas públicas. Grupo Executivo Interministerial. Brasília, DF: Ministério da Saúde, 2007.

BRASIL. Plano de Manejo da RESEX Marinha de Soure. Brasília: ICMBio, 2018.

CORIOLANO, L.N. Arranjos produtivos Locais do Turismo Comunitário: atores e cenários em mudanças. Fortaleza: UECE, 2009.

CORIOLANO, L.N.; LIMA, L.C. (orgs). Turismo comunitário e responsabilidade socioambiental. Fortaleza: EDUECE, 2003.

DENCKER, A.F.M. Pesquisa em Turismo: planejamento, métodos e técnicas. São Paulo: Futura, 2007.

FABEIRO, C.P. El desarrollo endógeno local, estudio de la actividad turística como forma de aprovechamiento de los recursos: aplicación al caso del Baixo Miño. Tesis (Doctorado en Ciencias Económicas) - Departamento de Economía Aplicada, Universidad de Vigo - Vigo, 2004.

FALCÃO, L.B. Turismo em RESEX: perspectivas de desenvolvimento, participação social e políticas públicas nas RESEX de Soure e de Curuçá no Pará. Dissertação (Mestrado em Turismo), Centro de Excelência em Turismo, UnB - Brasília, 2013.

FABRINO, N.H.; NASCIMENTO, E.P.; COSTA, H.A. Turismo de Base Comunitária: uma reflexão sobre seus conceitos e práticas. Caderno Virtual de Turismo, v.16, n.3, p.172-190, 2016. 
HAMOY, J.A. Turismo em unidades de conservação e o desenvolvimento local em Soure-PA. Dissertação (Mestrado em Planejamento do Desenvolvimento do Trópico Úmido) - Núcleo de Altos Estudos Amazônicos, UFPA - Belém, 2018.

HOLANDA, L.A. Empresarização do turismo de base comunitária. Caderno Virtual de Turismo. v. 16, n. 2, p. 249-262, 2016.

ICMBIO. Soure lança campanha para sensibilizar visitantes. 2013. Disponível em: <http://www.icmbio.gov.br/portal/ultimas-noticias/20-geral/4094-resex-de-sourelanca-campanha-para-sensibilizar-visitantes>. Acesso em: 23 nov. 2019.

ICMBIO. Dados gerais das unidades de conservação federais. Disponível em: $<$ http://www.icmbio.gov.br/portal/images/stories/servicos/geoprocessamento/DCOL/d ados tabulares/DadosGerais UC julho 2019.pdf>. Acesso em: 23 nov. 2019.

KRIPPENDORF, J. Sociologia do Turismo: para uma nova compreensão do lazer e das viagens. São Paulo: Aleph, 2003.

LOBATO, G.J.M.; MARTINS, A.C.C.T.; LUCAS, F.C.A.; MORALES, G.P.; ROCHA, T.T. Reserva Extrativista Marinha de Soure, Pará, Brasil: modo de vida das comunidades e ameaças ambientais. Biota Amazônia, v. 4., n. 4, p. 66-74, 2014.

MEDEIROS, L.; MORAES, P. Turismo e sustentabilidade ambiental: referências para o desenvolvimento de um turismo sustentável, Revista Meio Ambiente e Sustentabilidade, v.3, n.2, 2013.

MMA. Portaria n०. 76/03-N de 26 de novembro de 2003. Cria o Conselho Deliberativo da RESEXMS. Disponível em: <http://www.icmbio.gov.br/portal/images/stories/ imgs-unidades-coservacao/portarias/RESEX\%20Soure\%20Port\%2076\%20de\% 2026\%2011\%202003.pdf >. Acesso em: 23 nov. 2019.

MMA. Portaria no. 4 de 19 de maio de 2017. Modifica o Conselho Deliberativo da RESEXMS. Disponível em: <http://www.in.gov.br/materia/-/asset publisher Kujrw0TZC2Mb/content/id/19170503/do1-2017-07-12-portaria-n-4-de-19-de-maiode-2017-19170497>. Acesso em: 23 nov. 2019.

MTUR. Segmentação do turismo e o mercado. Brasília: Min. do Turismo, 2010.

MTUR. Dinâmica e diversidade do Turismo de Base Comunitária: desafio para a formulação de Política Pública. Brasília: Ministério do Turismo, 2010.

OLIVEIRA, A.M.S. Subsídios à gestão da reserva extrativista marinha de SoureMarajó-Pará: uma análise dos problemas e conflitos socioambientais. Dissertação (Mestrado em Gestão dos Recursos Naturais e Desenvolvimento Local na Amazônia). Núcleo de Meio Ambiente, UFPA - Belém, 2012.

PARATURISMO.

Marajó.

Disponível

em:

<http://www.paraturismo.pa.gov.br/vejamais natureza/marajo>. Acesso: 23/11/19.

PARATUR. Diagnóstico da Área e das Atividades Turísticas do Polo Marajó - PA. Belém: PARATUR, 2009.

PINHEIRO, L.C.F.; SOUZA, L.S.M.; PONTES, A.N.; SILVA, G.V.; LIMA, A.M.M. Educação ambiental e participação social. Sustentabilidade na Reserva Extrativista Marinha de Soure, Ilha do Marajó, Pará, Brasil. Educação Ambiental em Ação, n. 46, p. 1-12, 2013. Disponível em: <http://revistaea.org/artigo.php?idartigo=1701>. Acesso em: 23 nov. 2019. 
RISSO, L.C.A importância das Reservas Extrativistas para a discussão mundial da conservação da natureza. Revista Geografia e Pesquisa, v. 6, n. 1, p. 130-138, 2012.

SANTOS JÚNIOR, G.S. Ações e políticas públicas do Estado e sociedade acerca da geração de renda na RESEX de Soure/Marajó-PA. Dissertação (Mestrado em Planejamento do Desenvolvimento). Núcleo de Altos Estudos Amazônicos (NAEA), UFPA - Belém, 2006.

SOARES, J.B. Turismo de Base Comunitária: estudo de caso da Reserva Extrativista Marinha de Soure/PA. Monografia (Bacharelado em Turismo), Escola de Direito, Turismo e Museologia, UFOP - Ouro Preto, 2019.

SOURE. Turismo e Lazer. Disponível em: <https://www.soure.pa.gov.br/omunicipio/turismo-e-lazer/>. Acesso em: 23 nov. 2019.

SWARBROOKE, J. Turismo sustentável: conceitos e impacto ambiental. Trad. Margarete D.Pulido. 3 ed. São Paulo: Aleph, 2000.

TAKAHASHI, L.Y. Uso Público em Unidades de Conservação. Curitiba: Fundação O Boticário de Proteção à Natureza, 2004.

WWF. Manual de ecoturismo de base comunitária: ferramentas para um planejamento responsável. Brasília: WWF, 2003.

YIN, R.K. Estudo de Caso: planejamento e métodos. Porto Alegre: Bookman, 2015.

\section{Notas:}

Há uma valorização no segmento "natureza" das Fazendas Marajoaras e do Rio Paracauari; não havendo menção à RESEXMS no segmento "sol e praia".

${ }^{2}$ Não há menção das Praias de Barra Velha e do Pesqueiro serem no interior da RESEXMS.

Jônatas Bastos Soares: Universidade Federal de Ouro Preto, Ouro Preto, MG, Brasil.

E-mail: bastosjonatas@hotmail.com

Link para o currículo Lattes: http://lattes.cnpq.br/2501201197132910

Ricardo Eustáquio Fonseca Filho: Universidade Federal de Ouro Preto, Ouro Preto, MG, Brasil.

E-mail: ricardo.fonseca@ufop.edu.br

Link para o currículo Lattes: $\underline{\text { http://lattes.cnpq.br/160042442681122 }}$

Data de submissão: 22 de julho de 2019

Data de recebimento de correções: 14 de agosto de 2019

Data do aceite: 14 de agosto de 2019

Avaliado anonimamente 